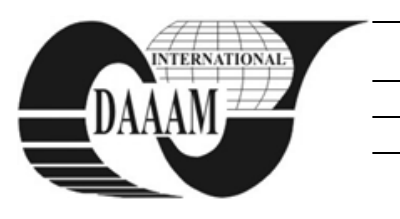

Annals of DAAAM for 2012 \& Proceedings of the 23rd International DAAAM Symposium, Volume 23, No.1, ISSN 2304-1382 ISBN 978-3-901509-91-9, CDROM version, Ed. B. Katalinic, Published by DAAAM International, Vienna, Austria, EU, 2012 Make Harmony between Technology and Nature, and Your Mind will Fly Free as a Bird Annals \& Proceedings of DAAAM International 2012

\title{
QUALITY IN INDUSTRIAL DESIGN
}

\author{
BOGZA, A[na] - M[aria]; SIMION, I[onel] \& ENACHE, I[oana] - C[atalina]
}

\begin{abstract}
The article presents the influence of quality in sensory design and also the importance of sensory analysis to improve the quality of industrial products. Pleasure associated with consumption is evaluated based on spontaneity and immediate gratification. Sensory satisfactions are in advantage from the intellectual ones. Consumer is becoming more demanding in this area in order to share an application at any time. Purchase act: product must be in line with consumer aspirations, surprise or ensure him that it pleased him throughout the cycle of use.
\end{abstract}

Keywords: design, sensory design, marketing sensorial, quality control

\section{INTRODUCTION}

The design of an industrial product, both on shapes and material, contributes significantly to the communication of feelings. Inclusion of these new priorities remains the responsibility of the entire company: marketing, design, engineering, production, quality.

One objective of sensory evaluation is to obtain information regarding how consumers perceive products. A second objective is to measure consumers: likes, dislikes and preferences. In our days, the company must be able to anticipate the consumers need [1] and the quality of the industrial product must tends to meet customer expectations [2] because the perceived quality has an important role in the cognitive and affective evaluation process [3].

Today we see an evolution of consumer behavior. Nowadays, the latter's present unpredictable behavior. Become mature, he explores the ability to analyze manufacturers to decode messages. He leaves a stereotype behavior in favor of coordinated actions, designed, especially adapted in context adapted to the objectives which he has set or expectations regarding the use. Consumers never cease to change their relationships with the product.

\section{INDUSTRIAL PRODUCTS}

"Industrial product" that is an invention of human life cannot mist and he cannot make exception to the rule. Industrial production has grown from a mass production model, designed primarily to meet the needs of a growing number of consumers and where a product performance and capacities are predominant to perform its function on a more competitive market.
This market is currently characterized by a higher segmentation and an increased need to customize industrial products [4]. These observations illustrate an evolution of the concept of industrial product during design period, that is representative of industrial and commercial making activity and the sensorial one, where a real control of the senses is deployed in "experiential" marketing approach based on competitive advantage associated with judicious use of an experience and sensorial information.

Better specified, comfort or industrial product quality is an important concern to producers. Traditionally, product specification is the result of methodologies with knowledge and experience in mechanics, physical, marketing, quality and style.

In a competitive growing environment, a challenge for constructor is to better respond to consumer expectations and demands controlling the atmosphere also offers industrial product. Sensory atmosphere of an industrial product can be defined as a set of sound, tactile, visual, olfactory and thermal stimulations.

Treatments beyond style, perception of atmosphere is the result of integration of conscious and unconscious sensory perceptions evolving in time depending on the situations of use.

To characterize the atmosphere, an approach is to give attention to its constituent components, approaching on one hand the question of use situations and on the other hand by industrial sensory dimensions. For instance, use statements referencing specific where situations that make the game sound or dynamic requirements significant for the user.

\section{THE QUALITY CONTROL}

Quality control is an essential function in which each company has to ensure customer satisfaction. To achieve this, different controls are in place to ensure product quality in various stages of manufacture. In most cases, these controls are made beginning with dimensional product measurements (sizes, weight etc), and rarely sensory measurements (visual, olfactory etc). Subjective quality, now relegated to second place after criteria "Use of products" currently occupies a central role for the customer. 
Customer no longer follows the product functionality. Customer wants a quality product. For this quality, it is necessary to carry out specific controls. The article presents the role of sensory analysis to improve visual inspection of products in a company.

In marketing field, several studies have been conducted on the perception of quality. This, it can be defined as follows: perceived quality is manifested as an idea in relation to the feelings and opinions collected [5].

In [3], perceived quality is defined as "an emotional state of an affective and cognitive evaluation process that occurs during a specific operation." Classic, quality tends to meet customer expectations [2]. Company must be able to anticipate this need and right to fill it [1].

Perception is an important step in sensory evaluation. It consists of three phases: activation of sensory receptors, acquisition of information sent by the receiver and translating information into sensations.

Thus, law Bouger-Weber [6] says that the differential threshold increases linearly with standard stimulus value. The doctor Gustav Fechner, who is also the inventor of the term Psychophysics, changed the law to make valid extreme values of stimuli.

Main characteristics of this movement are to consider that a feeling can never be measured directly. Man can measure and compare only if there is a perceived difference in sensation. Therefore, sensation varies with the logarithm of excitation [7].

Stevens [8] proposed a generalized Weber-Fechner law considering that the feeling is related to stimulation by a power law. Compared with the Weber-Fechner law, Stevens believed that it is not possible to measure a unique feeling independent.

Actually, an individual is able to tell if the sensation caused by $A$ is two times higher than that caused by $B$. Also, Stevens believed that if two dimensions of the stimuls intensity are equal, than the two indicators of sensation's intensity correspond and are also equal. Stevens' law expresses a sense of insensitive:

$$
\mathrm{I}=\mathrm{K} * \mathrm{~S}^{\mathrm{n}}
$$

Where:

\section{- I: intensity of sensation}

- S: stimul size

\section{- $k$ : constant of proportionality}

Nevertheless, these methods often do not respond to certain aspects of the problem of quality's subjectivity evaluation. Often it is necessary to combine several of these methods in order to achieve a comprehensive study. Therefore, each of these methods has strict specifications.
- Multi-criteria of decision: this area is to study the methods of choice based on several criteria. This method is based on an assessment of preferences.

- Data analysis: this area is a set of methods to extract information from large amounts of data.

- Measurement theory: this theory is based on mathematical foundations in order to measure the dimensions.

- Sensory analysis: it is a methodology based on the physical senses (sight, hearing, tactile, taste, smell) the measuring instrument in this case is a group of experts.

- Sensory physiology: is the study of the functioning of the senses.

- Psychology: it is interested in the perception of the object by topic.

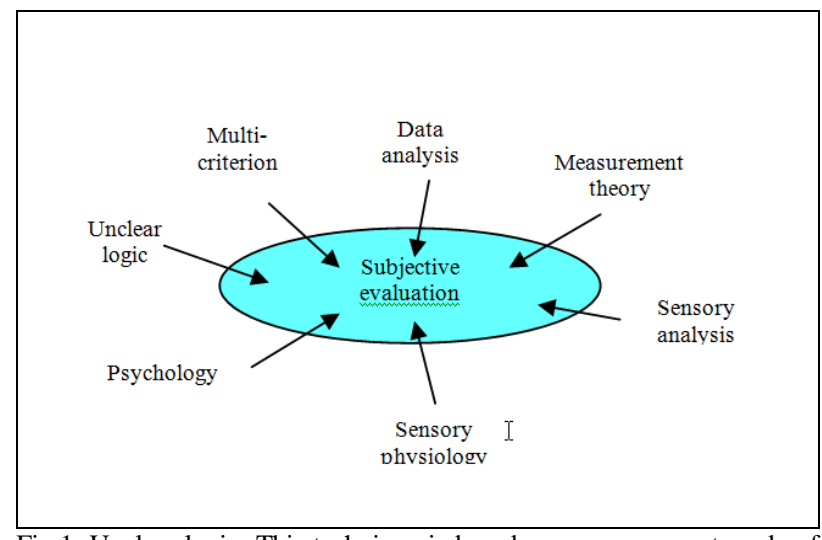

Fig.1. Unclear logic: This technique is based on an assessment made of the object on a scale from 0 to 1 [9].

\section{SENSORY DESIGN}

The industrial design is part of the overall and is involved in obtaining an object from the series. Sensorial design intends to address and control all the individual may be charged. By control we mean effective participation in the specifications before design (enrichment of the specification) identifying the quality performances of the future object and not only.

Indeed, we specify the qualitative performances due to their importance level (flexibility in making decisions during the design process), their assessment methods, verification methods, to useful measurement techniques and conformity quality relating to putting into production.

Sensorial design plays a major role in differentiating an object, a product, a space, a process, a finishing for developed industrial companies namely having already a control over the functional and technical problems of their products. The sensorial design represents one of the industrial design evolution and the involved persons being the engineer, the "marketer" and even the artist.

\subsection{Design and sensory design}

Sensory design is part of design. This has had several definitions illustrating its evolution. I have summarized 
the first founding definitions in a single formula ,design allows you to see". The result of design session can be seen, must be seen. The first practitioner designers „theorized" about these stylistic notions [10]. It is of course about a break of monopoly of the sensory visual way present thought the design process of an object.

Sensory design is a fundamental step, possible to control variables in designing a product that will be charged. Sensory design makes possible the control of all product characteristics from conception and development until the end of its life.

Initially, people transformed materials by using their art (glaziers, masons, cookers, weavers...) in order to get tangible results perceptible through great sensory ways (visual, olfactory, gustatory). Between art and creation, the level requirement of quality in achieving helped value, eventually manage a materialization of an object to high quality performances. Already, some devices are used to counteract the unpleasant effects.

Thus, people in perfume industry proposed a „masking” of sour tannin odors of leather gloves related to tanning procedures of the sheep skin.

The appearance of industrial design is tied to the desire to control diverse "product" offerings. Sensory differentiation takes place initially on a single sensory modality for food, than gaining all sensory modalities for all other sectors of consumer goods.

\subsection{Sensory assessment}

Sensory evaluation techniques have been developed to overcome the lack of measuring instruments to measure quality of food. Originally used to measure accordance quality, in a classical sense of evolution, those instruments and techniques were mobilized upstream downstream in the development process of product.

After several demonstrations of method transfer, the sensory assessment is interesting by all sensory ways [11], integrating new studies and new methodological tools from sensory design. It is even possible to ensure a relative representativeness on consumer perception in some contexts.

Olfactory sensory modality is one of the most complexes in term of sensory neuro-psychophysiological. As with taste issues, this sensory modality has a great variability between individuals.

Thus, "the nose" in perfume industry, is a person with a highly developed sense of smell allowing him to recognize the odors imperceptible, but also, to dissect every segment of flavor. He also has excellent olfactory memory, is able to remember all the smells felt.

In addition, he can mental assemble odors to create then perfumes. The odor fields is sensory reference developed by J. N. Jaubert, allowing acceleration of knowledge saving lots years of training.

\subsection{Difference between emotional desing and sensory one}

Emotional design refers to its origin, Kansei theory that led to Kansei engineering [12]. „Integrating subjective characteristics relative to users (such as feelings or emotions) has become a major problem for developing new techniques for product design. The main Japan response is Kansei engineering”.

But eventually, the difference and complementarity, the sensory design is interested only for conception of sensations, considering emotions as their consequence, too specific to the context and persons so you can control them from the beginning of the process of conception/creation. Sensory design gains predictability where emotional design gains in adaptation through designer results.

Emotional design is effective in formal aspects where the phenomenon of intersubjectivity prevents the sensorial design to use techniques of sensory assessment.

Thus, sensory marketing is a deep and complex concept, as it deals with the unconscious of the consumers: their perceptions, feelings and tastes. This approach is necessary as it allows controlling the atmosphere factors.

Then, the aim of our research will be to sum up the different techniques used by catering marketers which appeals to the senses of the consumer.

Customer (client) perceives the quality of industrial products from a marketing study done on the market. An industrial product, for market success must have a well established life cycle to influence consumer choice. Sensory metrology is to adapt supply to customer requirement. Sensory marketing has special tools for analysis the customer behavior. Sensory design is a fine thing and at the same time of great subtlety which has the ability to influence the perception we have for a product.

This technique also requires a cinematic analysis of objects as well as a work of all the sensory qualities not only visual (colors, material, shapes) but touch, olfactory, sound or taste. In the last years, the sensory design went from the field of scientific study to marketing for that matter.

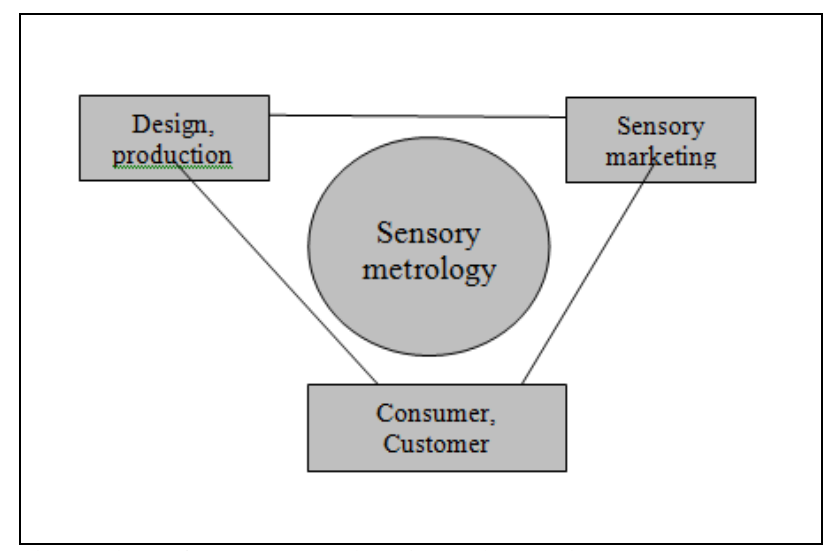

Fig. 3. Place of sensory metrology in product cycle

Companies have defined the objective of stimulating the five senses to attract consumers and to test their purchasing instinct. Namely, to create a product that will have, for customer, the better "perceived quality" (what is the quality that the consumer feels, but should not be confused with actual product quality). Sensory marketing 
has become a synthesis of what contemporary society demands from a firm and what a firm can do to create sensory experiences with the help of the five human senses.

\section{DISCUSSION}

The mental representation of physical objects in human cognitive systems has been extensively studied from the dual perspectives of cognitive science and neuroscience [13]. In the context of our research work on the evaluation of industrial's quality products, we were looking for a rapid method to measure the quality from the point of sensorial view. When a consumer expressed himself about the quality of the industrial products, he will most likely do it in his own words. This standpoint represents to the scientist a first established fact. Based on this short statement he has then to establish a correlation between analytical values and the consumer's judgment.

The objective evaluation of the quality of industrial product is a difficult task. This is mainly due to the fact that every single person is not necessarily influenced by the same sensory attributes and that the quality scale may vary strongly from one person to another. It is therefore extremely important to choose a representative sample of consumers to carry out the hedonic tests. Among the different sensory attributes describing industrial product, the quality is the one with the strongest effect.

\section{CONCLUSION}

Today we see an evolution of consumer behavior and for that the company must tend to meet customer expectations. The paper presents the industrial design concept, stressing on the interest on covering the requirements of the beneficiaries of the industrial products.

Today, for designing a product, it is necessary to know, understand and anticipate the needs of customers and the entire society. If working in areas that offer products that meet other needs than the basic ones then the company has found innovative ways to convey information.

In the study in this paper it has found that due to the contribution of cognitive psychology, a person compare information that he collects rational information but also affective information to his previous knowledge or experience. We have presented a series of articles relating to sensory design, trying to define what is, how it sells, about how it is put into practice in order to determine whether this trend is simply a marketing effect or a real evolution in the design field.

In the future works, we will focus our efforts on developing a new, non-destructive and rapid method to measure the quality of the industrial product from the sensorial point of view. The obtained results will be correlated with sensory analysis. It will be also necessary to solve the problems deriving from the development of the industrial product, often leading to very weak correlation indices between the analytical data and the sensory judgment.

This will be done by classifying the industrial product according to the hedonic scores given by the consumers prior to instrumental analysis. By doing this, the correlation between the consumer's appreciation and instrumental data strengthen considerably. A quality assessment model will be proposed. The quality of industrials products is an extremely complex matter, difficult to describe objectively. This will be also a subject to discuss in our future works.

\section{ACKNOWLEDGEMENTS}

The first author wishes to thank the Sectorial Operational Programme Human Resources Development 2007-2013 of the Romanian Ministry of Labour, Family and Social Protection through the Financial Agreement POSDRU/107/1.5/S/76813.

\section{REFERENCES}

[1] Lewis R.C., Booms B.H., (1993), The Marketing Aspects of Service Quality, Emerging Perspectives on Service Marketing, Berry L.L., Shostack L. and G. U. Eds

[2] Gotlieb J.-B., Grewal D., Brown S.W., (1994), Consumer Satisfaction and Perceived Quality: Complementary or Divergent Constructs, Journal of Applied Psychology, vol.79, $\mathrm{n}^{\circ}$ 6, pp. 875885

[3] Plichon V., (1998), La nécessité d'intégrer les états affectifs à l'explication du processus de satisfaction du consommateur (The need to integrate the affective states to explain the process of consumer satisfaction), Proceedings of the Conference of the French Association of Marketing, ${ }^{\circ} 14$, Vol 2, Ed. Saporta B. and Trinquecoste J. F, Bordeaux, IAE, pp. 671-694

[4] Nesa D., Crochemore S., (2004), Analyse sensorielle des materiaux d'habitacle automobile: Olfaction (Sensory analysis of materials for interior's car: Olfaction), Ed. Engineering techniques

[5] Balin S., Giard V., (2007), La qualité des services et leurs processus de production (The quality of the services and the productions processes), 7 th International Congress of Industrial Engineering, Trois-Rivières, Québec

[6] Loukil Hadj Kacem H., Bouhlel M.S., (2005), Mesure de la qualité des images par l'utilisation de la loi de Weber (Measurement of the image's quality through the use of Weber's law), 3rd International Conference: Sciences of Electronic, Technologies of Information and Telecommunications, Tunisie, 2005 American Marketing Association, Chicago, pp. 99-107

[7] Fechner G., (1860), The Elemente der Psychophysik (Éléments for psychophysical)

[8] Stevens S., (1964), Concerning the psychophysical power law, Quaterly Journal of Experimental Psychology, 16, pp. 383-385, 1964

[9] Club Crin, (1997), Unclear logic, subjective evaluation, Methods, Applications and Issues, The specifications Crin clubs, ECRIN Association

[10] Loewy R., (1952), La laideur se vend mal (Ugliness does not sell), Ed., Paris, 1952

[11] Bassereau J. F., (1995), Cahier des Charges Qualitatif Design, élaboration par le mécanisme des sens (Tender Qualitative Design, development by the mechanism of the senses), Phd thesis ENSAM, Paris

[12] Levy P., (2008), L'ingénierie KANSEI, ou comment lier affectivité et conception (Kansei engineering, or how to connect emotion and design), Ed. Techniques Ingénieur

[13] Sharlene D. Newman, Roberta L. Klatzky, Susan J. Lederman, Marcel Adam Just, (2005), Imagining material versus geometric properties of objects: an fMRI study, Cognitive Brain Research $23,235-246$ 